\title{
Psychological distress and its correlates among dental students: a survey of 17 Colombian dental schools
}

Kimon Divaris ${ }^{1 *}$, Ana Cristina Mafla², Laura Villa-Torres ${ }^{3}$, Marisol Sánchez-Molina ${ }^{4}$, Clara Liliana Gallego-Gómez ${ }^{5}$, Luis Fernando Vélez-Jaramillo ${ }^{6}$, Julián Andrés Tamayo-Cardona ${ }^{7}$, David Pérez-Cepeda ${ }^{8}$, Martha Ligia Vergara-Mercado ${ }^{9}$, Miguel Ángel Simancas-Pallares ${ }^{10}$ and Argy Polychronopoulou ${ }^{11}$

\begin{abstract}
Background: Links between the demanding nature of studies in the health sciences, students' personality traits and psychological distress have been well-established. While considerable amount of work has been done in medicine, evidence from the dental education arena is sparse and data from Latin America are lacking. The authors conducted a large-scale investigation of psychological distress among dental students in Colombia and sought to determine its curriculum and student-level correlates.

Methods: The Spanish version of the Derogatis' Symptoms Checklist Revised (SCL-90-R) was administered to all students officially registered and attending classes or clinics in 17 dental schools in 4 geographic districts of Colombia between January and April 2012. Additional information was collected on participants' socio-demographic information and first career choice, as well as school's characteristics such as class size. The Global Severity Index (GSI) score, a measure of overall psychological distress, served as the primary analytical endpoint. Analyses relied on multilevel mixed-effects linear and log-binomial regression, accounting for study design and sample characteristics.
\end{abstract}

Results: A total of 5700 dental students completed the survey, a response rate of $67 \%$. Pronounced gradients were noted in the association between socio-economic status and psychological distress, with students in higher strata reporting fewer problems. After adjustment for all important covariates, there was an evident pattern of increasing psychological distress corresponding to the transition from the didactic, to the preclinical and clinical phases of training, with few differences between male and female students. Independent of other factors, reliance on own funds for education and having dentistry as the first career choice were associated with lower psychological distress.

Conclusions: Levels of psychological distress correlated with students' socio-economic and study-level characteristics. Above and beyond the influence of person-level factors, variations in levels of distress paralleled specific transitional stages of the 5-year dental curriculum, providing opportunities for targeted interventions.

Keywords: Dental students, Psychological distress, Mental health, Psychopathology, Curriculum, Socioeconomic differences

\footnotetext{
* Correspondence: divarisk@dentistry.unc.edu

'Department of Pediatric Dentistry, UNC School of Dentistry, University of North Carolina-Chapel Hill, Chapel Hill, Brauer 228, CB\#7450, Chapel Hill NC 27599, USA

Full list of author information is available at the end of the article
} 


\section{Background}

A considerable body of literature has established the links between the demanding nature of studies in the health sciences, students' personality characteristics and manifestations of psychological distress [1-6]. Several reports indicate that students in medicine, dentistry, nursing and pharmacy experience high levels of perceived stress and psychological disturbance during the course of their studies, often at levels that are detrimental [3,7-9]. Prolonged psychological distress has been linked to a wide range of negative outcomes such as reduced academic performance, unprofessional conduct, burnout, and may even predispose to mental and physical disability [10-12].

While a substantial evidence-base on students' wellbeing exists in medicine, data in the arena of dental education are relatively sparse. Numerous studies suggest that dental students experience or report high levels of stress $[13,14]$, often higher compared to their medical counterparts $[6,7,15]$ yet investigations of psychological distress are uncommon. Although limited by small sample sizes, findings by Lloyd and Musser [16], Henning et al. [2] and Naidu et al. [17] showed that alarmingly high proportions (30-50\%) of dental students may be in the clinical range of psychological disturbance. Other investigators from Europe and Africa reported similar findings with regard to dental undergraduates' general health and psychological distress $[18,19]$. Noteworthy, a recent qualitative study in a Colombian dental school provided insights into critical factors that may be particularly stress and anxiety-inducing [20].

We embarked upon this investigation to add to the knowledge base of dental students' well-being and psychological distress. The literature reviewed by Alzahem and colleagues [13] offers a theoretical framing and justification for the selection of student- and institution-level, as well as extra-curricular factors as potential correlates of dental students' psychological distress. For example, financial difficulties and "overcrowding" at school [19], social class [21], gender and minority status [16], first career choice [22], have been previously reported to be associated with dental students' psychological well-being. Nevertheless, most studies have been limited by small sample sizes and no investigation to our knowledge has examined simultaneously 'distal' (e.g. socio-economic status, financial issues, career choice) and 'proximal' (e.g. gender, year of study) in among a large sample of dental students. Moreover, findings on the association of dental students' psychological distress with age, marital status and gender have not been consistent $[13,18]$. Therefore, to inform educators and researchers, but also sensitize and guide stakeholders in an area that this topic has received little attention, we conducted a large-scale investigation in 17 dental schools in Colombia. Our aims were to identify school and student-level correlates of psychological distress among dental undergraduates, including curriculum, career choice and socio-economic factors. Our hypothesis was that extra-curricular factors, above and beyond traditional person-level and demographic ones, are important determinants of students' psychological disturbance while in dental school.

\section{Methods}

During the 2011-12 academic year there were 33 Colombian dental schools, operating in 18 Universities and 4 geographic regions, with a total of 13,944 enrolled students. In Colombia the majority students enroll in dental school right after high school and admissions are based primarily upon competitive national exams and school-conducted interviews. Most schools are private and have tuition rates that vary, but are generally considered high. Dental studies are structured around a traditional, mostly lecture-based 5-year curriculum. The first two years are focused on didactic activities on biomedical and dental introductory courses. During the $2^{\text {nd }}$ but mainly the $3^{\text {rd }}$ year students undergo laboratory and pre-clinical training. Years 4 and 5 entail clinical training. Empirical observations indicate that only a small proportion of dental students complete their studies within the 10 semesters of the regular curriculum; most require 1-3 extra semesters to graduate, whereas considerable proportions drop out.

The investigators initially contacted 22 schools from 13 Universities to participate in the study, and 17 (77\%) schools agreed to do so. Although the resulting sampling frame of 8530 students does not constitute a probability sample of Colombian dental students, it represents $61 \%$ of the country's entire dental student population.

After obtaining ethical approval, investigators contacted and sought to enroll all students officially registered and attending classes or clinics in each school between January and April 2012. Of 8530 eligible individuals 5700 agreed to participate, an overall response rate of $67 \%$. Response rates varied and ranged from approximately $40 \%$ in UNAL - Bogotá and 42\% in UAM - Manizales to 100\% in UCC - Pasto, CURN - Cartagena and UMET -Barranquilla (Table 1). These differences were not strongly influenced by school characteristics. Nevertheless, we noted a statistically non-significant trend of lower response rate with increasing class (and school) size: "small schools": 78\%, "moderate size schools": 75\%, "large schools": 67\%; $\mathrm{P}=0.5$ ".

\section{Study instruments and procedures}

The survey instrument contained an array of five questionnaires that covered the following domains: socio-demography (6 items), first career choice (1 item), school and study-level information (6 items), 
Table 1 Description of the study sample frame and response rates, by geographical area, city and school

\begin{tabular}{|c|c|c|c|c|c|c|}
\hline & \multirow{3}{*}{$\frac{\text { Enrolled }}{\mathrm{N}}$} & \multicolumn{5}{|c|}{ Colombian Dental Students } \\
\hline & & \multicolumn{2}{|c|}{ Sampled } & \multicolumn{2}{|c|}{ Responded } & \multirow{2}{*}{$\frac{\text { Response Rate }}{\% \text { of sampled }}$} \\
\hline & & $\mathbf{N}$ & $\%$ of enrolled & $\mathbf{n}$ & column $\%$ & \\
\hline Total & 13,944 & 8530 & 61 & 5700 & 100 & 67 \\
\hline \multicolumn{7}{|l|}{ Geographical area } \\
\hline West & 5597 & 2769 & 49 & 1697 & 30 & 61 \\
\hline Central-East & 5473 & 3369 & 62 & 1921 & 34 & 57 \\
\hline Caribbean & 2570 & 2168 & 84 & 1921 & 34 & 89 \\
\hline Orinoquia & 304 & 224 & 74 & 161 & 3 & 72 \\
\hline \multicolumn{7}{|l|}{ City - School } \\
\hline Pasto - UCC & 375 & 375 & $100 \%$ & 375 & 6 & 100 \\
\hline Bucaramanga - USTA & 945 & 945 & & 599 & 10 & 64 \\
\hline Cartagena - CURN & 258 & 258 & & 258 & 5 & 100 \\
\hline Cartagena - UNICARTAGENA & 445 & 445 & & 405 & 7 & 91 \\
\hline Santa Marta - UNIMAGDALENA & 540 & 540 & & 378 & 6 & 70 \\
\hline Monteria - UNISINU & 163 & 163 & & 150 & 3 & 92 \\
\hline Medellín - UCC & 648 & 648 & & 380 & 7 & 59 \\
\hline Medellín - CES & 558 & 558 & & 350 & 6 & 88 \\
\hline Cali - UNICOC & 570 & 570 & & 334 & 6 & 59 \\
\hline Bogotá - UNAL & 548 & 548 & & 222 & 4 & 41 \\
\hline Bogotá - UNICOC & 500 & 500 & & 287 & 5 & 57 \\
\hline Bogotá - UAN & 250 & 250 & & 183 & 3 & 73 \\
\hline Bogotá - FUSM & 1126 & 1126 & & 630 & 11 & 56 \\
\hline Barranquilla - UMET & 505 & 505 & & 505 & 9 & 100 \\
\hline Villavicencio - UCC & 224 & 224 & & 161 & 3 & 72 \\
\hline Cartagena - UNISINU & 257 & 257 & & 225 & 4 & 88 \\
\hline Manizales - UAM & 618 & 618 & & 258 & 5 & 42 \\
\hline
\end{tabular}

psychological distress [Spanish version of the Symptoms Checklist 90-Revised (SCL-90-R) [23] - 90 items], perceived sources of stress (Spanish version of the modified Dental Environment Stress (DES) questionnaire [24,25] - 36 items), self-efficacy (Spanish version of the General Self-Efficacy Scale [26] - 10 items) and burnout (Spanish adaptation of the Maslach Burnout InventoryStudent Survey [27] - 15 items). The present manuscript contains results of analyses that were focused on symptoms of psychological distress (SCL-90-R); another report [28] presents findings regarding the perceived academic stressors (DES) among this sample of students.

Students were approached during scheduled class or seminar times. Investigators explained the purpose, anonymous nature and voluntary character of the study. The survey was administered in paper and pencil form which required approximately 25 minutes for completion.

\section{Measures and variables}

The main analytical endpoint (dependent variable) of the present report was psychological distress, as measured by the SCL-90-R. The SCL-90-R was introduced by Derogatis [29], and represents an evolution of earlier instruments measuring mental health, the SCL-90 [30] and the Hopkins Symptom Checklist [31]. The SCL-90-R is essentially a psychiatric self-report inventory, containing 90 items pertaining to various symptoms of psychological distress, such as "trouble remembering things" and "feeling nervous when you are left alone". Participants were instructed to indicate how much distress each item has caused during the "last 7 days including today" on a 5-point scale ranging from 0: not at all to 4: extremely.

The instrument has been used among diverse populations, and was shown to perform well in terms of reliability and internal consistency. The SCL-90-R was originally reported to be capturing nine symptom dimensions, namely somatization, obsessive-compulsive, 
interpersonal sensitivity, depression, anxiety, hostility, phobic anxiety, paranoid ideation, and psychoticism. However, this factorial structure was not subsequently confirmed [32]. Instead, the Global Severity Index (GSI), the mean score of all items, is considered to be the best representation of an overall psychological distress dimension. Other indices of distress that can be derived from the inventory are the Positive Symptom Distress Index (PSDI), representing the average score of items scoring above zero and the Positive Symptoms Total (PST), representing the number of items scoring above zero [29]. The PSDI can be interpreted as a symptoms "intensity" measure and the PST as a symptoms "extent" measure. For clinical and consultation purposes, normative scores and thresholds were initially suggested for adolescent and adult psychiatric patients and non-patients [23], however, classifications derived from these standard scores have been of limited utility across populations and settings [33,34]. In fact, because the structure and properties of the instrument tend to vary between populations, it has been recommended to empirically establish them in each new study sample [35]. Nevertheless, there is agreement regarding differences in reporting of psychological disturbance with the SCL-90-R between males and females, and therefore, as most previous investigations we obtained and reported sex-stratified estimates.

We collected additional information regarding participants' age [measured in years and coded as a categorical variable (under $18,18-<21,21-<24$, and 24 and over) for descriptive and as a continuous variable for analytical purposes]; sex; study year (1-5); sources of funding for studies (own sources only, own sources and loans, loans only); working while studying (yes/no) and socioeconomic level $(1-6$, where 1 is the lowest and 6 is the highest socio-economic stratum in Colombia). We also obtained information about the students' first career choice (dentistry vs. other). With regard to school-level variables, we recorded its private or public character and the average class size [coded arbitrarily as small $(<30)$, moderate $(30-60)$ and large (>60 students)].

\section{Analytical approach}

For initial data presentation and exploration we used descriptive statistics [simple proportions, means, standard deviations $(S D)$, medians and ranges], overall and stratified by sex. We used $\mathrm{X}^{2}$ tests and a $\mathrm{p}<0.05$ criterion to assess the distribution of covariates between male and female participants, and a $t$ test for the 'age' variable. The use of a $t$ test for non-normally distributed data was supported by the central limit theorem applied to a large sample [36].

\section{Factor analysis}

We explored the factor structure of SCL-90-R in the context of our study using iterated principal factor analysis with varimax rotation [37]. We empirically determined the factor structure by inspecting the corresponding Scree plot [38] and the proportion of 'variance explained'. The inspection of the scree plot has been shown to perform better than Kaiser's factorretention criterion of eigenvalue $\geq 1$, particularly in analyses with large number of items, where it consistently overestimates the number of factors to be retained [39]. Although we only used the GSI for analytical purposes, we generated and present internal consistencies (Cronbach's alphas), mean scores, SD and 95\% confidence intervals (CI) for all other SCL-90-R derived indices to offer an opportunity for comparisons with other samples and studies that employ these other metrics.

Modeling of the psychological disturbance index (SCL-90-R) The sample's clustered nature of observations (respondents were "nested" in dental schools and these "nested" within cities and geographic regions) dictated the use of analytical methods based on multilevel modeling [40]. To determine the impact of student- and school-level factors on psychological disturbance throughout the 5-year curriculum we used multilevel mixed-effects multivariate linear regression of the GSI. We accounted for the clustering of observations and study sample design by specifying three nested random-effect terms, one for each sample "level", geographic region, University/city, and school, confirming their inclusion by a Likelihood Ratio (LR) "chunk" test [41] and a p-value criterion of $<0.2$. In all models we entered a priori terms for age, sex, socioeconomic status and study year. Inclusion of additional covariates was based on forward selection and LR tests with a p-value criterion of $<0.2$. To allow for nonhomogeneous effects of age, socio-economic status and first career choice between males and females and across study years, we included a five-way interaction term between these variables. We based our inference on crude and adjusted beta coefficients and corresponding $\mathrm{p}$-values using a $\mathrm{p}<0.05$ criterion, as well as inspection of predictive marginal effects [42].

\section{Modeling of psychological morbidity "high scorers"}

To quantify the impact of student and school-level factors on the prevalence of high psychological morbidity we used a second series of multivariate models based on log-binomial regression. First, we generated normalized GSI (T) scores centered at 50 separately for males and females and, as in previous studies [29,43-45], used a $\mathrm{T}$ score $\geq 63$ definition for a psychological morbidity "high scorer". This cut-off score resulted in classifying $8 \%$ of students of both sexes as "high scorers". Subsequently, we fitted two logbinomial regression models separately for male and 
female "high scorer" and obtained adjusted prevalence ratios (PR) and 95\% CI. Our choice of log-binomial versus the more common logistic regression was based on the fact that odds ratios obtained from logistic regression tend to overestimate the true effect size when the outcome under study is common $(>20 \%)$ and because prevalence ratios are more readily interpretable compared to odds ratios in cross-sectional studies [46,47]. We used Stata version 12.1 (StataCorp LP, College Station, TX, United States) for all data analyses.

\section{Ethical approval}

The study was approved by the Health Sciences Ethics Committee of Universidad Cooperativa de ColombiaPasto (No. CECS02-12).

\section{Results}

The mean age of the 5700 dental students was 21 years, with approximately two-thirds being female and having dentistry as their first career choice (Table 2). Most did not work while in dental school and were in socio-

Table 2 Demographic characteristics of the study sample, stratified by sex

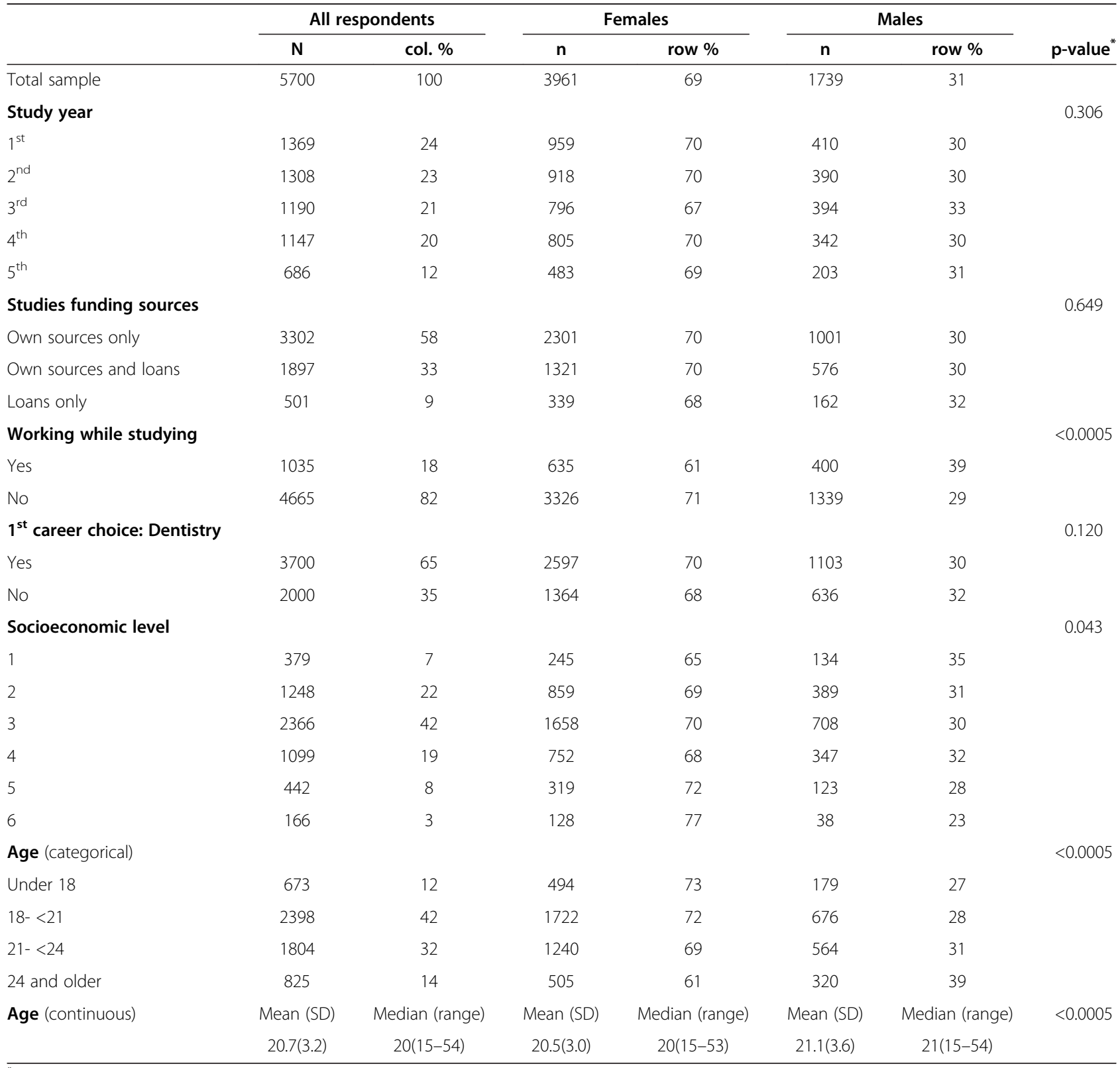

* Chi-square test for categorical variables and t test for the continuous age variable. SD $=$ Standard Deviation 


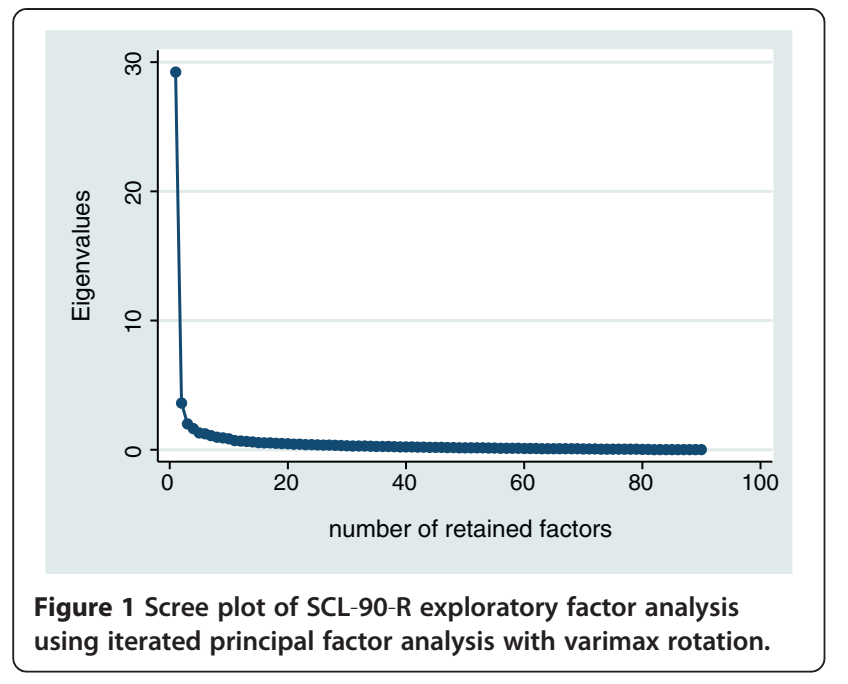

economic strata 2-4 reflecting low-to-middle socioeconomic status. The number of participants gradually decreased across study levels, ranging from over $13001^{\text {st }}$ and $2^{\text {nd }}$ years to $6865^{\text {th }}$ year students.

\section{Psychological distress}

The exploratory iterated principal factor analysis confirmed the presence of one dominant factor in SCL-90-R, explaining over eight times the variance explained by the second factor (Figure 1). Cronbach's alpha for the GSI was high, 0.98 . The mean (SD) GSI scores were: overall1.03 (0.69); females-1.08 (0.69); males-0.91 (0.68). Among female and male participants who had normalized T-scores of $\geq 63$ and were classified as "high scorers" ( $8 \%$ of total), these estimates were 2.62 and 2.48 , respectively. Although the GSI was used as our primary

Table 3 Results of multilevel* multivariate linear regression modeling of the SCL-90-R Global Severity Index (GSI) score

\begin{tabular}{|c|c|c|c|c|}
\hline \multirow[b]{2}{*}{ Covariates } & \multicolumn{2}{|c|}{ Beta coefficient } & \multirow[b]{2}{*}{$95 \% \mathrm{Cl}$} & \multirow[b]{2}{*}{ p-value } \\
\hline & unadjusted $^{\dagger}$ & adjusted $^{\ddagger}$ & & \\
\hline Age (continuous) & 0.01 & 0.00 & $-0.01,0.00$ & 0.53 \\
\hline \multicolumn{5}{|l|}{ Sex (ref: male) } \\
\hline Female & 0.16 & 0.16 & $0.12,0.20$ & $<0.005$ \\
\hline \multicolumn{5}{|l|}{ Marital status (ref: single) } \\
\hline Married & 0.08 & 0.05 & $-0.02,0.13$ & 0.16 \\
\hline Working while studying & -0.03 & -0.01 & $-0.01,0.04$ & 0.73 \\
\hline \multicolumn{5}{|l|}{ Financial support (ref: own funds) } \\
\hline Own funds + loans & 0.08 & 0.05 & $0.01,0.09$ & 0.01 \\
\hline Loans only & 0.14 & 0.11 & $0.05,0.18$ & $<0.005$ \\
\hline Dentistry was first career choice & -0.11 & -0.11 & $-0.15,-0.07$ & $<0.005$ \\
\hline \multicolumn{5}{|l|}{ Socio-economic stratum (ref: $1^{\text {st }}$ ) } \\
\hline $2^{\text {nd }}$ & -0.05 & -0.06 & $-0.13,0.02$ & 0.16 \\
\hline $3^{\text {rd }}$ & -0.07 & -0.08 & $-0.16,0.00$ & 0.04 \\
\hline $4^{\text {th }}$ & -0.17 & -0.16 & $-0.24,-0.07$ & $<0.005$ \\
\hline $5^{\text {th }}$ or $6^{\text {th }}$ & -0.12 & -0.12 & $-0.21,-0.02$ & 0.02 \\
\hline \multicolumn{5}{|l|}{ Study year (ref: $1^{\text {st }}$ ) } \\
\hline $2^{\text {nd }}$ & 0.09 & 0.09 & $0.03,0.14$ & $<0.005$ \\
\hline $3^{\text {rd }}$ & 0.07 & 0.08 & $0.02,0.13$ & 0.01 \\
\hline $4^{\text {th }}$ & 0.25 & 0.25 & $0.19,0.31$ & $<0.005$ \\
\hline $5^{\text {th }}$ & 0.19 & 0.18 & $0.11,0.25$ & $<0.005$ \\
\hline \multicolumn{5}{|l|}{ Institution type (ref: public) } \\
\hline Private & -0.07 & -0.08 & $-0.27,0.11$ & 0.39 \\
\hline \multicolumn{5}{|c|}{ Mean class size per semester (ref: <30) } \\
\hline $30-60$ students & -0.03 & -0.05 & $-0.23,0.12$ & 0.55 \\
\hline$>60$ students & -0.09 & -0.05 & $-0.26,0.16$ & 0.66 \\
\hline
\end{tabular}

" Model included nested random effect terms to account for clustering of observations within school, city/University, and geographic region. tmodel included only random-effects for school, city/University and geographical area. łmodel included additionally all other variables presented in the table.

$\mathrm{Cl}=$ Confidence Interval. 
analytical endpoint, to enable comparisons with previous and future studies we present PST, PSDI and the 9 SCL-90-R dimensions scores in the supplemental material (Additional file 1: Table S1). To enable additional comparisons across studies and samples we additionally present the percentile distributions of the GSI, PST and PSDI indices by sex (Additional file 1: Table S2).

\section{Correlates of psychological distress}

The final multilevel regression model for GSI is presented in Table 3. After adjustment for all important covariates (age, marital status, working while studying, institution type and class size), sex, financial support sources, socio-economic status, career choice and study year, remained significantly associated with psychological distress. Females, students whose first career choice was not dentistry, those with loan-supported studies and in lower socio-economic strata reported higher levels of distress. The crude effect estimate corresponding to the difference between males and females was attenuated to a small degree (8\%) after adjustment, with the multivariate beta coefficient indicating an adjusted difference of 0.16 points on the GSI scale. The strong effect of socio-economic status was virtually homogeneous among male and female participants (Figure 2, top panel). Above and beyond these associations, there was an evident pattern of increasing psychological distress corresponding to the transition from the didactic/basic science $\left(1^{\text {st }}\right.$ and $\left.2^{\text {nd }}\right)$, to the preclinical $\left(3^{\text {rd }}\right)$ and clinical $\left(4^{\text {th }}\right.$ and $5^{\text {th }}$ years) stage of the curriculum. Particularly among females, the transition into the clinical training phase was associated with a pronounced increase in GSI scores (Figure 2, bottom panel). Noteworthy, while the multilevel model's random-effect term for school participation was significant $(b=0.13 ; 95 \% C I=0.09,0.19 ; P=0.03)$, the terms for city/University and geographic reason were non-significant, indicating little additional variance explained after accounting for school participation.

In Table 4 we present results of the psychological disturbance analysis for males and females. Being married emerged as an important correlate of being a "high scorer", with $83 \%$ increase in likelihood among males. Reliance on loans was strongly associated with distress particularly among females $(\mathrm{PR}=2.01 ; 95 \%$ $\mathrm{CI}=1.47$, 2.76). Similarly, dentistry as a first career choice was important protective factor for female

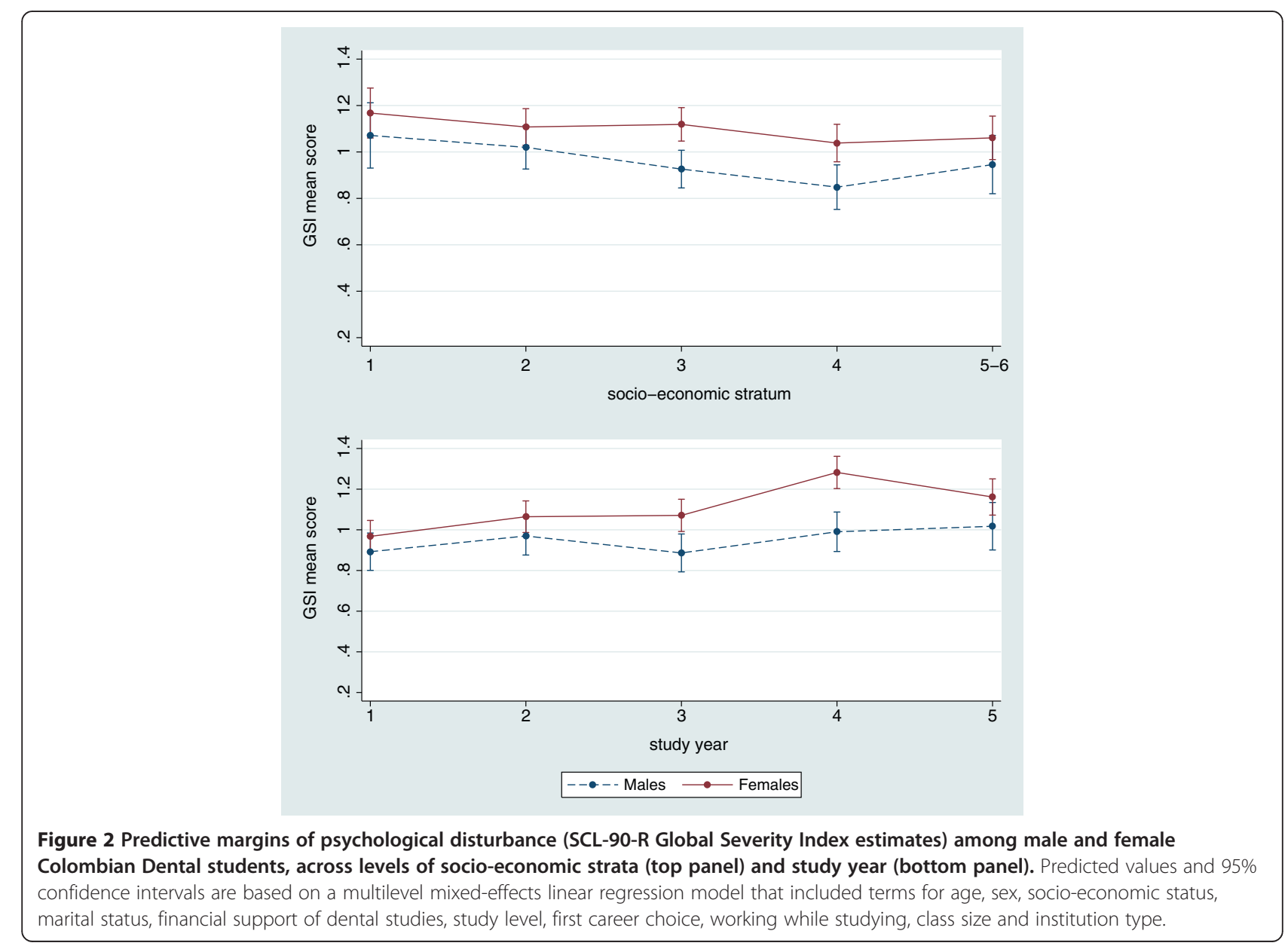


Table 4 Results of multivariate log-binomial regression modeling of high psychological disturbance (Global Severity Index T-score $\geq 63$ )

\begin{tabular}{|c|c|c|c|c|c|c|}
\hline \multirow[b]{2}{*}{ Covariates } & \multicolumn{3}{|c|}{ Females } & \multicolumn{3}{|c|}{ Males } \\
\hline & $\begin{array}{c}\text { Prevalence } \\
\text { Ratio }\end{array}$ & $95 \% \mathrm{Cl}$ & p-value & $\begin{array}{c}\text { Prevalence } \\
\text { Ratio }\end{array}$ & $95 \% \mathrm{Cl}$ & p-value \\
\hline Age (continuous) & 0.99 & $0.95,1.03$ & 0.637 & 1.01 & $0.97,1.06$ & 0.571 \\
\hline \multicolumn{7}{|l|}{ Marital status } \\
\hline Single & 1.00 & referent & & 1.00 & referent & \\
\hline Married & 1.38 & $0.97,1.96$ & 0.073 & 1.83 & $1.07,3.14$ & 0.027 \\
\hline Working while studying & 0.91 & $0.69,0.18$ & 0.471 & 0.85 & $0.59,1.23$ & 0.394 \\
\hline \multicolumn{7}{|l|}{ Financial support } \\
\hline Own funds & 1.00 & referent & & 1.00 & referent & \\
\hline Own funds + loans & 1.27 & $1.00,1.61$ & 0.052 & 1.49 & $1.05,2.12$ & 0.026 \\
\hline Loans only & 2.01 & $1.47,2.76$ & $<0.0005$ & 1.29 & $0.71,2.26$ & 0.420 \\
\hline Dentistry was first career choice & 0.66 & $0.64,0.81$ & $<0.0005$ & 0.83 & $0.60,1.14$ & 0.253 \\
\hline \multicolumn{7}{|l|}{ Socio-economic stratum } \\
\hline $1 s t$ & 1.00 & referent & & 1.00 & referent & \\
\hline $2^{\text {nd }}$ & 1.08 & $0.67,1.75$ & 0.758 & 1.35 & $0.74,2.47$ & 0.329 \\
\hline $3^{\text {rd }}$ & 1.17 & $0.74,1.87$ & 0.502 & 0.92 & $0.50,1.71$ & 0.793 \\
\hline $4^{\text {th }}$ & 0.97 & $0.57,1.63$ & 0.900 & 0.88 & $0.43,1.78$ & 0.716 \\
\hline $5^{\text {th }}$ or $6^{\text {th }}$ & 0.95 & $0.53,1.70$ & 0.850 & 0.85 & $0.36,2.00$ & 0.704 \\
\hline \multicolumn{7}{|l|}{ Study year } \\
\hline $1 s t$ & 1.00 & referent & & 1.00 & referent & \\
\hline $2^{\text {nd }}$ & 1.27 & $0.87,1.84$ & 0.216 & 1.42 & $0.85,2.38$ & 0.184 \\
\hline $3^{\text {rd }}$ & 1.44 & $0.98,2.12$ & 0.063 & 0.94 & $0.53,1.68$ & 0.842 \\
\hline $4^{\text {th }}$ & 2.44 & $1.70,3.50$ & $<0.0005$ & 1.54 & $0.91,2.62$ & 0.111 \\
\hline $5^{\text {th }}$ & 1.89 & $1.23,2.91$ & 0.004 & 1.63 & $0.90,2.94$ & 0.104 \\
\hline \multicolumn{7}{|l|}{ Institution type } \\
\hline Public & 1.00 & referent & & 1.00 & referent & \\
\hline Private & 0.93 & $0.68,1.26$ & 0.627 & 0.72 & $0.48,1.09$ & 0.117 \\
\hline \multicolumn{7}{|l|}{ Mean class size per semester } \\
\hline$<30$ students & 1.00 & referent & & 1.00 & referent & \\
\hline $30-60$ students & 1.20 & $0.88,1.61$ & 0.245 & 0.94 & $0.60,1.48$ & 0.795 \\
\hline$>60$ students & 1.22 & $0.88,1.70$ & 0.223 & 0.83 & $0.46,1.49$ & 0.524 \\
\hline
\end{tabular}

students, and was associated with $34 \%$ decreased prevalence $(\mathrm{PR}=0.66 ; 95 \% \mathrm{CI}=0.64,0.81)$. The clinical training stage was the peak period for "being a case" for both sexes vs. the first year (Figure 3): $4^{\text {th }}$ year among females-PR $=2.44(95 \% \mathrm{CI}=1.70,3.50)$ and $5^{\text {th }}$ year among males-PR $=1.54(95 \% \mathrm{CI}=0.90,2.94)$.

\section{Discussion}

In this study of student- and curriculum-level correlates of psychological distress among Colombian dental students we found that both demographic and socioeconomic (sex, socio-economic status, and financial support sources) and study-related (career choice and study-year) characteristics influenced the levels of students' psychological disturbance. This report builds upon a robust sample of almost 6 thousand students to add to the knowledge base of health science students' psychological distress, and provides insights into this important issue among an under-studied group of dental students, in Latin America. Although direct comparisons with other samples and populations should be made with caution, the levels of psychological distress in this group of dental students were considerably higher compared to previously reported estimates among young non-clinical samples. The findings of possible associations between dental curriculum stage and psychological morbidity provide insights into educational events and transitions that may be sources of distress for dental undergraduates. 

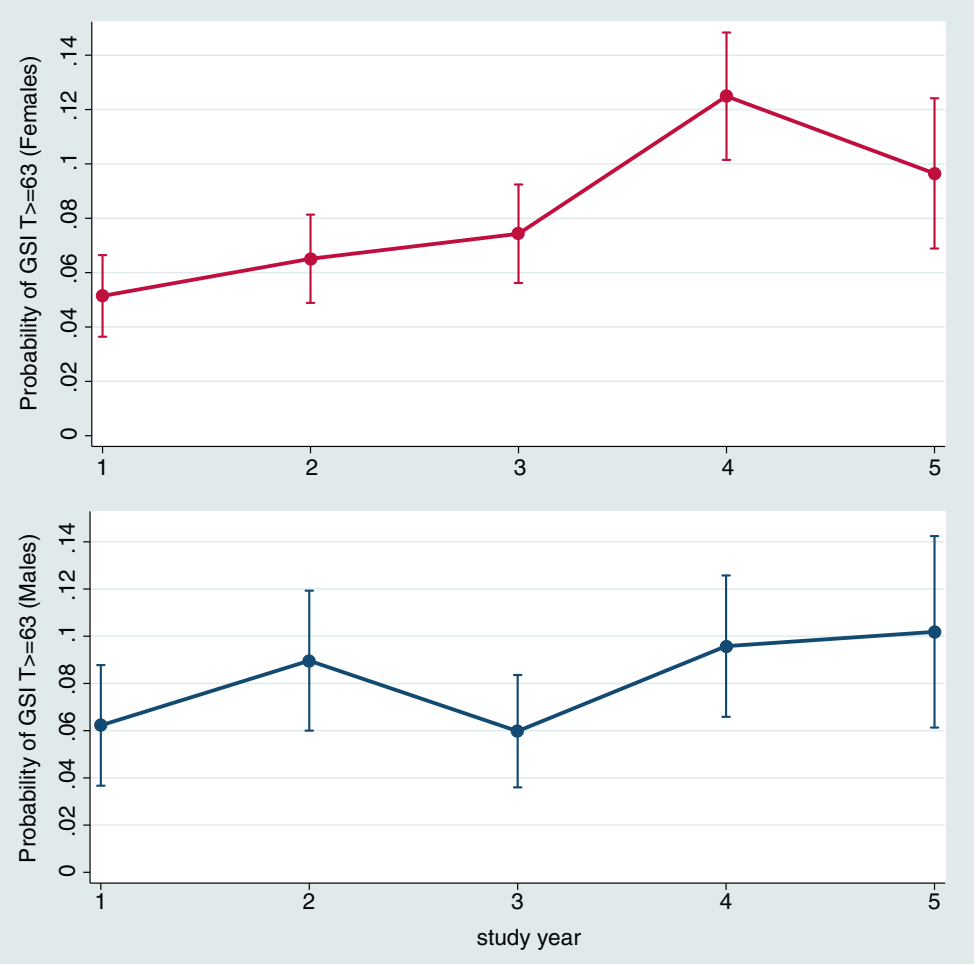

Figure 3 Predictive margins of psychological morbidity "caseness" (SCL-90-R Global Severity Index T-score $\geq 63$ ), across levels of study year for female and male dental students. Predicted probabilities and $95 \%$ confidence intervals are based on a multivariate log-binomial regression model that included terms for age, sex, socio-economic status, marital status, financial support of dental studies, study level, first career choice, working while studying, class size and institution type.

As mentioned previously, cross-cultural comparisons of SCL-90-R norms and scores is not well-supported [34]. Nevertheless, we empirically compared and found the present study's GSI estimates (mean scores) to be higher compared to previous non-clinical sample norms among adolescents and students that have been published in the US-0.31 to 0.76 [23], New Zealand-0.88 [48], Spain-0.50 [49]. This observation is consistent with previous data indicating that dental students experience and demonstrate higher levels of stress and distress compared to age- and sex-matched norms, and compared to students of other disciplines [6,7,15-17]. Findings of high levels of psychological distress among dental students come as no surprise. One source of distress is likely inherent in the complex nature of dental education, which, beyond the acquisition of academic and interpersonal competencies, requires that undergraduates develop precision technical and surgical skills, and perform non-reversible operative procedures prior to graduation [14]. Additional sources may include students' young age and personality traits $[2,50]$, social, cultural and financial pressures unrelated to studies [51], and others.

As in previous investigations employing the same instrument (SCL-90-R), female dental students reported higher levels of psychological distress compared to their male counterparts. Given the 'universality' of this by-sex difference among normative and populationbased samples, this finding should not be attributed to characteristics of the dental education environment. However, it is consistent with previous reports of females being more expressive of their emotions [52]. Findings relative to the protective or detrimental role of non-academic factors such as marital status, career choice, and financial pressures reiterate the necessity to view professional studies and students within their family, social and economic context. While factors such as financial difficulties and dissatisfaction with career choice $[19,22]$ may exert additional pressures to students and be detrimental, other factors such as being married and working while studying may serve as buffers of coping and social support, and thus, be beneficial. Interestingly, in a survey of a US dental school, students rated non-academic support programs higher than ones that were focused on academic skills [53] providing support to the notion that nonacademic influences are equally and perhaps more important than academic ones.

The variation of psychological distress across study years above and beyond all other demographic, socio- 
economic, and institution-level parameters is noteworthy. Distress levels increased overall, but pronounced spikes were evident in the transition to from the didactic/ basic science, preclinical and clinical phases of the training. This is consistent with evidence of perceived stress escalating over time [52] or varying according to curricular landmarks such as transition from pre-clinical to clinical training $[17,54]$. These findings are likely demonstrations of excessive demands placed upon the students; work overload, little time, insufficient coping resources, non-academic distractions or combinations of those, can readily precipitate psychological disturbance and morbidity $[54,55]$.

Our findings must be regarded in view of the study's limitations. The participants did not represent a probability sample of all Colombian dental students, and response rates varied considerably between the 17 participating dental schools. Moreover, due to student attrition, the sample size decreased progressively from the $1^{\text {st }}$ to the $5^{\text {th }}$ study year. We cannot support that study non-participation was independent of psychological distress levels thus both these factors are potential threats to the external validity of our findings. Moreover, and although self-reported instruments are routinely used for screening purposes in psychiatry and social/behavioral epidemiology, students' reports are also prone to biases of unknown magnitude and direction. Finally, our inferences with regard to differences in the levels of psychological distress by study-level were based on cross-sectional observations rather than longitudinal data, and therefore, should be interpreted with caution. A prospective survey design capturing student-level longitudinal data throughout the dental curriculum would enable investigators to make stronger inferences regarding the trends in psychological morbidity across the stages of dental training.

\section{Conclusions}

The issue of alarmingly high levels of psychological distress during medical training is well-established, and evidence now accumulates in dentistry. Acknowledging the limitations of our cross-sectional survey, we support that both personal (sex, socio-economic status, and financial support sources) and curriculum or institution-level factors (career choice and study-year) are associated with dental undergraduates' psychological distress. Under the conditions of our study, variations in levels of distress paralleled specific transitional stages of the 5-year dental curriculum, providing opportunities for targeted interventions in the curriculum. Based on these findings we further suggest that schools and states give special consideration to the students' social and economic conditions, with the aim of allocating appropriate support to those most in need. Nonetheless, evidence of systematic application and evaluation of means to improve dental and health science students' educational well-being is lacking and should be prioritized. It is imperative that such interventions, beyond evidence-based and effective, are participatory, socially and culturally-appropriate, and sustainable.

\section{Consent}

Written informed consent was obtained from all participating dental students for the publication of this report, in compliance with the Health Sciences Ethics Committee of the Universidad Cooperative de Colombia Pasto (ACT No. ECHS02-12).

\section{Additional file}

Additional file 1: Psychological distress estimates derived from the Symptom Check List 90-Revised (SCL-90-R).

\section{Abbreviations}

Cl: Confidence interval; GSI: Global severity index; PR: Prevalence ratio; PSDI: Positive symptom distress index; PST: Positive symptoms total; SCL-90-R: Symptoms checklist revised; SD: Standard deviation.

\section{Competing interests}

The authors declare that they have no competing interests.

\section{Authors' contributions}

$\mathrm{KD}$ conducted the analysis and wrote the first draft of the manuscript; ACM conceived and coordinated study, participated in data collection and cleaning, and wrote the first outline of the manuscript; LVT participated in the study design, instrument piloting, and critically revised the manuscript; MSM, CLGG, LFVJ, JATC, DPC, MLVM, MASP participated in the planning of the study, data collection and entry, and critically revised the manuscript; AP oversaw the data design and analysis, and critically revised the manuscript. All authors approved the final version of the manuscript.

\section{Acknowledgments}

The authors would like to thank the following individuals Gloria Cristina Aranzazu Moya (Universidad Santo Tomás), Ruth Ángela Gómez Scarpetta (Universidad Cooperativa de Colombia - Villavicencio), Farith González Martínez (Universidad de Cartagena), Natalia Fortich Mesa (Corporación Universitaria Rafael Núñez), Luis Armando Vila Sierra (Universidad del Magdalena), Héctor Ángel Polanco Narváez and Carlos Durán Meléndez (Universidad Nacional de Colombia - Bogotá), María José Villalobos Castro (Universidad Antonio Nariño - Bogotá), Diana Parra Galvis (Institución Universitaria Colegios de Colombia - Bogotá), Liliana María Duque Restrepo (Universidad Autónoma de Manizales) for their assistance in data collection and all dental students for their participation.

\section{Funding}

The study was supported by funding from the Comité Nacional para el Desarrollo de la Investigación (CONADI) of Universidad Cooperativa de Colombia and the División de Investigación Asociación Colombiana de Facultades de Odontología, and by study infrastructure from all participating institutions.

\section{Author details}

'Department of Pediatric Dentistry, UNC School of Dentistry, University of North Carolina-Chapel Hill, Chapel Hill, Brauer 228, CB\#7450, Chapel Hill NC 27599, USA. ${ }^{2}$ Grupo de Investigaciones en Odontología (GIOD), Facultad de Odontología, Universidad Cooperativa de Colombia-Pasto, Calle 18 No. 47-150, Pasto, Nariño, Colombia. ${ }^{3}$ Department of Health Behavior, Gillings School of Global Public Health, University of North Carolina-Chapel Hill, CB \#7440, Chapel Hill, North Carolina, USA. ${ }^{4}$ Facultad de Odontología, 
Universidad Metropolitana, Calle 76 No. 42-78, Barranquilla, Atlántico, Colombia. ${ }^{5}$ Facultad de Odontología, Universidad Cooperativa de Colombia - Medellín, Carrera 47 No. 37 Sur 18, Medellín, Antioquia, Colombia. ${ }^{6}$ Facultad de Odontología, Universidad CES, Calle 10 A No. 22-04, Medellín, Antioquia, Colombia. ${ }^{7}$ Institución Universitaria Colegios de Colombia sede Cali, Transversal 25 No. 18-21, Cali, Valle del Cauca, Colombia. ${ }^{8}$ Facultad de Odontología, Fundación Universitaria San Martín, Carrera 15a No. 60-80, Bogotá, Colombia. ${ }^{9}$ Facultad de Odontología, Universidad del Sinú - Montería, Campus Elías Bechara Zainúm, Calle 38 Carrera 1 W Barrio Juan XXIII. Bloque 5 Piso 2 PBX, Montería, Córdoba, Colombia. ${ }^{10}$ Facultad de Odontología, Universidad del Sinú - Cartagena, Av. Pedro de Heredia, Sector Amberes, Cartagena de Indias, Colombia. ${ }^{11}$ Department of Preventive and Community Dentistry, School of Dentistry, National and Kapodistrian University of Athens, Goudi 11527, Greece.

Received: 22 August 2012 Accepted: 17 June 2013

Published: 26 June 2013

\section{References}

1. Wolf TM: Stress, coping and health: enhancing well-being during medical school. Med Educ 1994, 28:8-17.

2. Henning K, Ey S, Shaw D: Perfectionism, the imposter phenomenon and psychological adjustment in medical, dental, nursing and pharmacy students. Med Educ 1998, 32:456-464.

3. Dutta AP, Pyles MA, Miederhoff PA: Stress in health professions students: myth or reality? A review of the existing literature. J Natl Black Nurses Assoc 2005, 16:63-68.

4. Dyrbye LN, Thomas MR, Shanafelt TD: Systematic review of depression, anxiety, and other indicators of psychological distress among U.S. and Canadian medical students. Acad Med 2006, 81:354-373.

5. Marshall LL, Allison A, Nykamp D, Lanke S: Perceived stress and quality of life among doctor of pharmacy students. Am J Pharm Educ 2008, 72:137.

6. Birks Y, McKendree J, Watt I: Emotional intelligence and perceived stress in healthcare students: a multi-institutional, multi-professional survey. BMC Med Educ 2009, 9:61.

7. Schmitter M, Liedl M, Beck J, Rammelsberg P: Chronic stress in medical and dental education. Med Teach 2008, 30:97-99.

8. Davis EL, Tedesco LA, Meier ST: Dental student stress, burnout, and memory. J Dent Educ 1989, 53:193-195.

9. Guthrie E, Black D, Bagalkote H, Shaw C, Campbell M, Creed F: Psychological stress and burnout in medical students: a five-year prospective longitudinal study. J R Soc Med 1998, 91:237-243.

10. Pasnau RO, Stoessel P: Mental health service for medical students. Med Educ 1994, 28:33-39.

11. Dyrbye LN, Massie FS Jr, Eacker A, Harper W, Power D, Durning SJ, Thomas MR, Moutier C, Satele D, Sloan J, Shanafelt TD: Relationship between burnout and professional conduct and attitudes among US medical students. JAMA 2010, 304:1173-1180.

12. Lempp H, Seale C: The hidden curriculum in undergraduate medical education: qualitative study of medical students' perceptions of teaching. BMJ 2004, 329:770-773.

13. Alzahem AM, van der Molen HT, Alaujan AH, Schmidt HG, Zamakhshary MH: Stress amongst dental students: a systematic review. Eur J Dent Educ 2011, 15:8-18.

14. Divaris K, Barlow PJ, Chendea SA, Cheong WS, Ntounis A, Dragan IF, Hamlin J, Hosseinzadeh L, Kuin D, Mitrirattanakul S, Mo'nes M, Molnar N, Perryer G, Pickup J, Raval N, Shanahan D, Songpaisan Y, Taneva E, Yaghoub-Zadeh S, West $K$, Vrazic D: The academic environment: the students' perspective. Eur J Dent Educ 2008, 12:120-130.

15. Murphy RJ, Gray SA, Sterling G, Reeves K, DuCette J: A comparative study of professional student stress. J Dent Educ 2009, 73:328-337.

16. Lloyd C, Musser LA: Psychiatric symptoms in dental students. J Nerv Ment Dis 1989, 177:61-69.

17. Naidu RS, Adams JS, Simeon D, Persad S: Sources of stress and psychological disturbance among dental students in the West Indies. J Dent Educ 2002, 66:1021-1030.

18. Humphris G, Blinkhorn A, Freeman R, Gorter R, Hoad-Reddick G, Murtomaa H, O'Sullivan R, Splieth C: Psychological stress in undergraduate dental students: baseline results from seven European dental schools. Eur J Dent Educ 2002, 6:22-29.
19. Omigbodun OO, Odukogbe AT, Omigbodun AO, Yusuf OB, Bella TT, Olayemi O: Stressors and psychological symptoms in students of medicine and allied health professions in Nigeria. Soc Psychiatry Psychiatr Epidemiol 2006, 41:415-421.

20. Jaramillo G, Caro H, Gomez Parra ZA, Moreno Bedoya JP, Restrepo Pabon EA, Suarez Mejia MC: Stress and triggering devices in dental students of Universidad de Antioquia. Rev Fac Odontol Univ Antiog 2008, 20:49-57 [article in Spanish].

21. Fredericks MA, Mundy P: Dental students: relationship between social class, stress, achievement, and attitudes. J Am Coll Dent 1967, 34:218-228.

22. Sugiura G, Shinada K, Kawaguchi Y: Psychological well-being and perceptions of stress amongst Japanese dental students. Eur J Dent Educ 2005, 9:17-25.

23. Derogatis L: SCL-90-R: Symptom Checklist-90-R. Administration, scoring, and procedural manual. Minneapolis: National Computer Systems; 1994.

24. Polychronopoulou A, Divaris K: Perceived sources of stress among Greek dental students. J Dent Educ 2005, 69:687-692.

25. Fonseca J, Divaris K, Villalba S, Pizarro S, Fernandez M, Codjambassis A, Villa-Torres L, Polychronopoulou A: Perceived sources of stress among Chilean and Argentinean students. Eur J Dent Educ 2013, 17:30-38.

26. Bäßler J, Schwarzer R: Evaluación de la autoeficacia. Adaptación española de la escala de autoeficacia general [Measuring generalized self-beliefs: a Spanish adaptation of the General Self-Efficacy scale]. Ansiedad y Estrés 1996, 2:1-8

27. Schaufeli WB, Martinez IM, Pinto AM, Salanova M, Bakker AB: Burnout and engagement in university students: A cross-national study. J Cross Cult Psychol 2002, 33:464-481.

28. Divaris K, Polychronopoulou A, Villa-Torres A, Mafla AC, Aranzazu-Moya G, González-Martínez F, Vila-Sierra LA, Fortich-Mesa N, Gómez-Scarpetta RA, Duque-Restrepo LM: Extracurricular Influences on Perceived Stress in a Large Cohort of Colombian Dental Students. J Dent Educ. In Press.

29. Derogatis LR: SCL-90-R Administration, Scoring \& Procedures Manual-II. Towson: Clinical Psychometric Research; 1983.

30. Derogatis LR, Lipman RS, Covi L: SCL-90. An outpatient psychiatric rating scale-preliminary report. Psychopharmacol Bull 1973, 9:13-17.

31. Derogatis $L R$, Lipman RS, Rickels K, Uhlenhuth EH, Covi L: The Hopkins Symptom Checklist (HSCL): a measure of primary symptom dimensions. In Psychological Measurements in Psychopharmacology: Modem Problems in Pharmacopsychiatry, vol. 7. Edited by Pichot P. Basel, Switzerland: Karger; 1974:79-110.

32. Cyr JJ, McKenna-Foley JM, Peacock E: Factor structure of the SCL-90-R: is there one? J Pers Assess 1985, 49:571-578.

33. Todd DM, Deane FP, McKenna PA: Appropriateness of SCL-90-R adolescent and adult norms for outpatient and nonpatient college students. J Couns Psychol 1997, 44:294-301.

34. Clark A, Friedman MJ: Factor structure and discriminant validity of the SCL-90 in a veteran psychiatric population. J Pers Assess 1983, 7:396-404

35. Hoeffding W, Robbins $\mathrm{H}$ : The central limit theorem for dependent random variables. Duke Math J 1948, 15:773-780.

36. Kaiser HF: The varimax criterion for analytic rotation in factor analysis. Psychometrika 1958, 23:187-200.

37. Cattell RB: The scree test for the number of factors. Multivar Behav Res 1966, 1:245-276.

38. Zwick WR, Velicer WF: Comparison of five rules for determining the number of components to retain. Psychol Bull 1986, 99:432-442.

39. Snijders TAB, Bosker RJ: Multilevel analysis. An introduction to basic and advanced multilevel modeling. 2nd edition. London: Sage Publications; 2012

40. Kleinbaum DG, Klein M: Modeling strategy for assessing interaction and confounding, Logistic Regression. New York: Springer; 2010:203-239.

41. Graubard BI, Korn EL: Predictive margins with survey data. Biometrics 2004, 55:652-659.

42. de Groot M, Jacobson AM, Samson JA, Welch G: Glycemic control and major depression in patients with type 1 and type 2 diabetes mellitus. J Psychosom Res 1999, 46:425-435.

43. Beutel ME, Höflich A, Kurth RA, Reimer C: Who benefits from inpatient short-term psychotherapy in the long run? Patients' evaluations, outpatient after-care and determinants of outcome. Psychol Psychother 2005, 78:219-234.

44. Elsenbruch S, Benson S, Hahn S, Tan S, Mann K, Pleger K, Kimmig R, Janssen OE: Determinants of emotional distress in women with polycystic ovary syndrome. Hum Reprod 2006, 21:1092-1099. 
45. Barros AJ, Hirakata VN: Alternatives for logistic regression in cross-sectional studies: an empirical comparison of models that directly estimate the prevalence ratio. BMC Med Res Methodol 2003, 3:21.

46. Skov T, Deddens J, Petersen MR, Endahl L: Prevalence proportion ratios: estimation and hypothesis testing. Int J Epidemiol 1998, 27:91-95.

47. Barker-Collo SL: Culture and validity of the Symptom Checklist-90-Revised and Profile of Mood States in a New Zealand student sample. Cultur Divers Ethnic Minor Psychol 2003, 9:185-196.

48. Vallejo MA, Jordán CM, Díaz MI, Comeche MI, Ortega J: Psychological assessment via the internet: a reliability and validity study of online (vs paper-and-pencil) versions of the General Health Questionnaire-28 (GHQ-28) and the Symptoms Check-List-90-Revised (SCL-90-R). J Med Internet Res 2007, 9:e2.

49. Jessee SA, O'Neill PN, Dosch RO: Matching student personality types and learning preferences to teaching methodologies. J Dent Educ 2006, 70:644-651.

50. Verger P, Combes JB, Kovess-Masfety V, Choquet M, Guagliardo V, Rouillon F, Peretti-Wattel P: Psychological distress in first year university students: socioeconomic and academic stressors, mastery and social support in young men and women. Soc Psychiatry Psychiatr Epidemiol 2009, 44:643-650.

51. Sanders AE, Lushington K: Sources of stress for Australian dental students. J Dent Educ 1999, 63:688-697.

52. Musser LA, Lloyd C: The relationship of marital status and living arrangement to stress among dental students. J Dent Educ 1985, 49:573-578.

53. Polychronopoulou A, Divaris K: A longitudinal study of Greek dental students' perceived sources of stress. J Dent Educ 2010, 74:524-530.

54. Goh AMY, Chiu E: Campus mental health: Are we doing enough? Asia Pac Psychiatr 2009, 1:58-63.

55. Almeida DM, Kessler RC: Everyday stressors and gender differences in daily distress. J Pers Soc Psychol 1998, 75:670-680.

doi:10.1186/1472-6920-13-91

Cite this article as: Divaris et al:: Psychological distress and its correlates among dental students: a survey of 17 Colombian dental schools. BMC Medical Education 2013 13:91.

\section{Submit your next manuscript to BioMed Central and take full advantage of:}

- Convenient online submission

- Thorough peer review

- No space constraints or color figure charges

- Immediate publication on acceptance

- Inclusion in PubMed, CAS, Scopus and Google Scholar

- Research which is freely available for redistribution 